\title{
Conceptual Framework for Speech Language Pathologists to Work with Migrants: A Focus on Malta
}

\author{
Helen Grech (Corresponding author) \\ Department of Communication Therapy, Faculty of Health Sciences \\ University of Malta, Msida MSD 2080, Malta \\ E-mail: helen.grech@um.edu.mt
}

Li Rong Lilly Cheng

5500 Campanile Drive, San Diego State University, San Diego, CA 92182, USA

E-mail: lcheng@mail.sdsu.edu

Received: August 30, 2016 Accepted: October 19, 2016 Published: October 21, 2016

doi:10.5296/jei.v2i2.9962 URL: http://dx.doi.org/10.5296/jei.v2i2.9962

\begin{abstract}
The goal of this paper is to describe the current state, needs and values of migrants with a focus on relevant global issues and Malta as a case study. It also aims to review services offered to these migrants, identify aspects that require attention and draw up a framework that could be applied to enhance services to the culturally diverse populations, particularly speech therapy. The health care services offered to migrants are reviewed in the light of attitudes and expectations. Professional perceptions and competences to work with these populations are also discussed and perceptions of migrants about services offered to them are taken into consideration. Issues related to equitable professional practice and the training of health care professionals to address needs of the cultural diverse community are discussed. Strategies to implement the conceptual framework are suggested.
\end{abstract}

Keywords: Culturally diverse population, Migrants and speech therapy, Speech language therapy, Framework for speech therapy, Irregular migrants

\section{Introduction}

\subsection{Irregular Immigrants in Europe with a Focus on Malta}

During the past decade or so thousands of asylum seekers (Note 1) and migrants (Note 2) have left primarily African countries (such as Somalia, Sudan, Eritrea and Nigeria) via Libya 
to reach Europe looking for better living conditions and often seeking refugee status. The European Southern Frontier has been inundated with boats full of irregular migrants reaching various shores such as Malta, Greece, Italy, and adjacent countries/islands. For example, in Malta, until 2002 there were relatively few (less than 100) detainees at one time, most did not apply for asylum and only in extreme cases did any of these individuals stay in detention for years (JRS, Malta, 2007). From 2002 onward, a significant number of irregular migrants continued to arrive on Maltese shores; this phased out between mid-2008 and early 2011 as a result of the Italian-Libyan Treaty on Friendship. However, with Libya's more recent upheaval and instability, irregular immigrants from sub-Saharan Africa escalated once again. The number of irregular immigrants arriving by boat in Malta in 2013 was 2008; an increase of $6.2 \%$ when compared to the recorded number of 1890 immigrants in 2012 (National Statistics Office, 2014). This is a significant number of irregular migrants landing in Malta considering that the Maltese archipelago is the most overcrowded EU member state and that its population is less than half a million. The majority of irregular migrants are granted humanitarian protection and only a few are given refugee status.

Border control of migration and asylum policies have become stricter in the EU in recent years and has also become a priority in the EU's agenda along with terrorism and drug trafficking (Dauvergne, 2008). Bigo and Guild (2005) claim that there are tighter controls over the release of visas for entry into the EU. The UNHCR (2012) predicted a significant increase in the arrival of such 'unauthorized' persons as a result of the political instability in Libya and other North African territories, and possibly consequent to poor economic opportunities in their home countries. Pickering and Gerard (2011) claim that Malta has a very strict and lengthy detention policy that discourages and 'punishes' the arrival of 'asylum seekers'. This policy excludes pregnant women and those arriving with children. European and International organisations such as Medecins Sans Frontierers (MSF) reported the shameful conditions in detention centres: in 2009, for example, the latter suspended its aide of medical services into Malta's Detention Centres (MSF, 2009).

Gerard and Pickering (2012) evaluated interview responses of 26 adult females (average age of 29 years) who had travelled 'unauthorized' to Malta and who had 'humanitarian protection', as well as those of 2 representatives from the Maltese Government and 2 from a non-government organization (NGO). Since the majority of women asylum seekers arrive in Malta from Somalia, most of the female interviewees in this study hailed from this country and reported that they had children and partners who were not living with them at the time. Gerard and Pickering (2012) reported that on arrival of these migrants, border control contained and punished these women; this behaviour extends even once these females are legally accepted and released, presumably as a consequence of EU restrictions on refugee protection. Four of the women interviewed by the said authors claimed to be pregnant though it was suspected by the authors that most of these females were expectant mothers through 'forced pregnancies'. Responses from NGO representatives claimed that around half the women in detention were pregnant (some of whom were possibly raped while in transit).

The women also reported difficulties with surviving in Malta once they were released from detention, primarily because of difficulties with securing employment and the conditions of 
accommodation because of what they perceived to be social and economic rejection. The scarcity of public child care facilities also limited the ability of these single mothers to seek employment. The open detention centres which are offered to most of these women on being released were reported as being over-crowded and limited in terms of sanitary conditions and accessibility to regular public transport and shopping facilities. The final focus of the respondents' stories was the impact of the Dublin II Regulation. It is claimed that the Dublin II Regulation (EC 343/2003) ('Dublin II') places a lot of responsibility on the country where these migrants arrive, very often those geographically on the Central Mediterranean border, such as Malta. It is also difficult for asylum seekers to travel within the EU given that the Dublin 11 Regulation states that application for asylum will have to take place at the first EU country of arrival; besides, should there be attempts to re-apply for asylum in another EU country this is not allowed and anyone who sneaks out may be sent back to the EU state where the asylum application would have been submitted. This created the situation of over-crowding of 'irregular' migrants in Maltese territory; a situation which neither the Maltese Government nor most of the asylum seekers seem to be happy with. One in five migrant interviewees in Gerard and Pickering's study reported that as a result of the Dublin 11 Regulation they were returned back to Malta and in some instances, repeatedly, at the expense of being excluded from family and social networks. One NGO respondent claimed that in some instances these women deliver their child/ren in other member states so as to secure citizenship of the child in the country where s/he is born and consequently releasing the mother from her return to Malta. Moreover, the negative psychological impact of being forced to remain in Malta was reported by the respondents. It seems that the social and political environment in Malta, combined with the implementation of the Dublin II Regulation, makes it difficult for such migrants to transfer legal status. The reports of the interviewees in the above-mentioned study point towards a sense of internal exclusion and insecurity, particularly for women.

Bradford and Clark (2014) interviewed some irregular migrants in Malta who had gone through the process of detention but were released in open centres or were living in rented accommodation. Similar stories to those above were reported. It was noted that these migrants are easily distinguished from Maltese society, particularly in terms of skin colour and vernacular, and an increasing sense of xenophobia is being felt in Malta. The European Network against Racism (2010) reports Malta as having the highest incidence rate of discrimination in comparison with EU countries who participated in its survey. Pisani and Azzopardi (2008) affirm how Malta has been strongly criticized by European and International organisations on how it handles the arrival of irregular migrants or asylum seekers. Mainwaring (2012) refers to the Maltese policy in dealing with irregular migrants, whereby every irregular migrant is issued with a removal order. Once such individuals apply for asylum (and most of them do soon after arrival) the removal order is lifted; however, they remain in detention for as long as 18 months. As per Maltese law, i.e., Immigration Act of 1970, detention results from the issuing of a removal order. The detention centres are actually 'run down' ex-colonial military barracks. More specifically, the 'unacceptable' conditions of the detention centres, the lengthy and comprehensive process of making decisions about the status of these immigrants while in detention and the negative impact that 
the detention policy has on these people resulted in Malta receiving very negative feedback on how it handles irregular immigration. Pisani and Azzopardi state that the Maltese government has been making a stand in terms of its position in prioritizing migration control and spends a significant proportion of its budget on detention facilities. There is political agreement locally to retain the detention policy. Meanwhile, there have been consistent pleas from the Government of Malta to the EU Commission for assistance with control of immigrants, and to share the burden by relocating some of these immigrants who land primarily in Malta as well as by offering other ways of support (including financial).

The perceptions of the Maltese regarding refugees and migrants in Malta were captured in a survey conducted by UNHCR (2012). Just over half the Maltese respondents reported that too many immigrants are arriving on Maltese shores and the majority indicated that these migrants should adapt to the Maltese culture and life style. Meanwhile, the Commissioner for Human Rights reported concern at attitudes of racism and xenophobia in Malta (Commissioner for Human Rights, 2011). In fact anti-immigration campaigns have emerged in the past decade in Malta. The Commissioner urged the Maltese Government to introduce programmes that facilitate local integration of these migrants. However, given the global insecurity arena, this is quite a challenge. On the other hand, the Prime Minister of Malta claimed that the escalating number of illegal immigrants and asylum seekers in Malta is becoming a national security issue. (The Sunday Times of Malta, July 14, 2013).

The only country in the European Union that has a one and a half year detention policy for irregular migrants is Malta. Mainwaring (2012) interprets this as an endorsement of the Maltese government to treat the arrival of irregular migrants in Malta as a crisis. The author made such claims following the conducting of interviews in Malta between 2008 and 2009 with government officials, representatives from non-governmental organisations (NGOs), as well as with 'irregular' migrants. During the interviews the Maltese authorities mentioned that the 18 month detention serves the purpose of restricting, putting off and containing the incoming flow of migrants and to encourage repatriation of those who already landed on the island as well alleviate the perceived crisis inherent to the significant influx of irregular immigrants. The standpoint taken by the Maltese Government is that the Maltese archipelago is the most overcrowded EU member state. The Government implemented an assisted voluntary repatriation scheme. The resistance to improving the state of detention centres could be a way to encourage voluntary repatriation. All these 'manoeuvres' point towards Malta's standpoint of controlling and restricting irregular migration to its shores.

However, on interviewing migrants and refugees, Mainwaring (2012) was given the impression that detention would not put off irregular migrants from landing on Maltese shores; some claimed that they had no point of return and could even stay as long as needed in detention; others claimed that this was not the country they wished to land in and therefore it was more a coincidence rather than a premeditated arrival; whereas others claimed that they were unaware of Malta's detention policy before they landed. Hence, the immigrants perceived Malta's detention policy as ineffective despite the perception of the national authorities. Mainwaring claims that detention gives the impression that immigrants are 'criminalised', leading to a negative attitude towards detainees in the national population. 
Meanwhile, Malta has been warned that using such long term detention as a means of deterring incoming migrants and encouraging repatriation of those who are already ashore is not in line with the international regarding refugees (UN High Commissioner for Refugees, 2009).

\subsection{EU Asylum and Immigration Law, Policy and Implementation}

The law and policy of the European Union (EU) are inter-related in that the former shapes EU policy. Therefore, what the EU wants to achieve and how this is implemented is decided in the context of its legal framework. The EU policy of returning irregular migrants is embedded in EU immigration policy. This policy addresses measures to be used for forcible return of these individuals. However, this policy also addresses the implementation of 'temporary custody', also referred to as administrative detention. The EU Justice and Home Affairs domain has a programme to assist EU member states financially and otherwise to develop facilities to retain these asylum seekers during the administrative detention phase. Meanwhile, the EU has been striving to increase co-operation with Libyan authorities over the management of these migrants. There are documented reports from sources such as Amnesty International of detainees in Libya that have been subjected to brutal experiences and suffering as a result of the fragile situation in the country.

In the regional report on the detention of asylum seekers and illegal immigrants in 10 new member states of the EU (JRS, 2007) it is stated that EU member states seem to have their own version of law and policies in dealing with such situation. As an example Malta's Immigration Act (Act IX of 1970 as subsequently amended, Chapter 217 of the Laws of Malta) legalises EU policy so that the island caters for administrative detention of illegally staying $3^{\text {rd }}$ country nationals, until deportation can be effected. Landing on Malta irregularly is not a criminal offence; however, the penalty is that of detention (for months) pending repatriation. Since 2005 those asylum seekers whose application is still pending after 12 months' detention are released to the community to await outcome of their application. Special concessions are given to minors and pregnant immigrants. It seems that while awaiting the verdict most of the immigrants engage in 'illegal unemployment' as they are not allowed to engage in gainful employment during the detention period. Consequently, Maltese legislation, policy and the current state of affairs does not seem to have been effective in discouraging more irregular migrants. Moreover, it seems that some migrants in European countries such as Malta are subjected to racial discrimination, possibly as a result of historically stereotypical perceptions. Consequently, some of them may struggle with integrating and finding accommodation to the extent that they end up clustered in ghettos and segregated (NCPE, 2012).

\subsection{EU Health Care for Irregular Migrants}

Wylie, McAllister, Davidson, and Marshall (2013) indicated that migrants are often medically under-served, have difficulty with accessing health service and consequently, they are less likely to benefit from rehabilitation services such as speech therapy. Albarran and colleagues (2011) attribute this to language barriers, financial matters, limited knowledge of the local health care system and expectations of these populations. 
In terms of article 10 of the Refugees Act of the Laws of Malta, asylum seekers and illegal immigrants are entitled to state health care service. In its 2009 report, Médicins Sans Frontièrs (MSF) claimed that the sub-standard quality and over-crowding of detention centres in Malta has resulted in long-term physical and psychological health problems in these migrants. For example, infectious/communicable diseases such as chicken pox, tuberculosis, scabies, gastro-enteritis and respiratory tract infections were spreading to the extent that $35 \%$ of medical consultations reported such conditions. Although detainees were expected to be isolated, the protocols for isolation were unclear. In some instances detainees were isolated at the discretion of guards, with the consequence that some healthy individuals ended up in isolation quarters with sick people. In case of mental health problems MSF reported that anxiety, fear and frustrations among these detainees could exacerbate the suppressed psychological distress and hardship they encountered in their countries of origin and during the desert and sea crossings. These individuals often end up feeling defeated and hopeless. MSF reported that $30 \%$ and $25 \%$ of the detainees they assessed had symptoms of depression and anxiety, respectively. Given the available literature and statistics, children of such migrant families seem to be at risk of health related difficulties and may encounter difficulties in receiving services as a result of financial, communication and educational limitations.

Such barriers are bound to be common across individuals who try to access the various health care services including primary health care, under which speech therapy service often falls. Crowley and colleagues (2013) tried to identify and address the barriers to accessing speech therapy service in Ghana that persons with communication difficulties were facing: only around 10 university-qualified speech language pathologists (SLPs) are practicing in Ghana, with the ratio of SLPs to people being approximately 1 per 2.5 million, and most of the SLPs are non-Ghanaian. In many ways most of the people living in Ghana, particularly in the rural and remote areas, face similar barriers to those faced by irregular migrants reaching European shores. The more 'vulnerable' groups such as the elderly, those from lower income backgrounds, and those who do not speak English or one of the more widely spoken languages in the mainland have limited access to the service. For example, although they come from the 'same' cultural background, receiving speech therapy from professionals who do not comprehend nor use their vernacular proficiently (in the absence of qualified interpreters) may present a challenge. The general comment of the Committee on Economic, Social, and Cultural Rights (CESCR) (2000) urges states to take adequate budgetary, judicial and other measures to address and implement accessibility of the right to appropriate, non-discriminatory health services. Discrimination in access to health care on the grounds of race, colour, sex, language, religion, political or other opinion that reflects the right to health is therefore considered unacceptable.

\subsubsection{Equitable Professional Practice}

Footer and Rubenstein (2013) state that health care professionals should be provided with appropriate standards of education and training as well as abide by professional ethical codes of conduct even in challenging environments. Health care professionals are committed to being respectful and empathic and to providing an egalitarian, caring and holistic service tailor-made to the client's needs. They are expected to alleviate suffering and promote the 
well-being of individuals. The International Classification of Functioning, Disability and Health (ICF) (World Health Organization, 2001) shifted the focus of management of individuals with communication and swallowing difficulties from the medical model to the biopsychosocial approach. Consequently, the individual and environmental factors that affect the expression of disabilities and accessibility to services are taken into consideration. However, the ICF does not give importance to other issues which may be may pertain to people with disabilities, such as poverty, exploitation and harassment. SLPs need to focus on all these needs and assist the clients with optimising their potential to function better and to participate actively within their family and community.

This is particularly applicable when working with migrant populations where it is considered necessary that SLPs have a set of clinical competencies to manage cultural and linguistic diversity. Kathard and Pillay (2013) suggest that the social and human rights models would be amalgamated with ICF to offer a better and more equitable professional practice. They recommend that developing professional frameworks for under-serviced populations should shift from having the individual as the focus of service provision towards a population-based philosophy, whereby people with disabilities and communities are collectively engaged in the process of care of the individuals with disabilities.

Smith and Reynolds (2002) stress the need to balance the harmonization of service provision with specific cultural needs. In the case of offered health care, this may clash with beliefs, behaviours, attitudes or values conveyed by cultural wisdom. For example, Topouzkhanian and Mijiyawa (2013) mention the cutting of the lingual frenulum of a child with delayed onset of speech and language acquisition or inserting hot stones under the tongues of children who are dysfluent. Culturally embedded practices need to be considered by health professionals including SLPs, when trying to plan strategies for prevention, identification and intervention as well as providing family guidance. Language and culture are linked together; since language is a property of the self it contributes to our individual character. Culture influences our vision of the world, our beliefs, our ways of communicating, and the different styles of interaction. This merge of language and culture is the essence of how SLPs need to manage clients with diverse cultures.

The World Report on Disability (World Health Organization and The World Bank, 2011) urges policy makers to address the barriers to health care service access that exist for people with disabilities. Rodriguez (2005) reports that culturally and linguistically diverse children with disabilities are at risk of being placed in a classroom in which little attention is given to students' academic instructional needs and characteristics. This translates also to persons with communication and feeding difficulties. Pillay (2013) refers to the estimated 215 million international migrants (legal and illegal) and argues that World Report on Disability under-represents migrants with disabilities even though these are a vulnerable group in terms of health care, as indicated above. It seems that SLPs play a role in this issue; they could focus on guiding and supporting their clients to make information, professional service and skills accessible to them. Hartley (1998) claims that SLPs have to advocate for an effective policy in a cultural context where communication disability may be little understood or appreciated, highly stigmatized, and may also be low on the service providers' and 
politicians' list of priorities. Given this advocacy it is questionable whether the educational programs of health care professionals are catering for such needs and providing their students with the tools and mechanism to attain such competency.

\subsubsection{Training Health Care Professionals to Address Needs of the CDP}

Professionals working with cultural diverse groups are often faced with specific constraints. Wickenden, Hartley, Kariyakaranawa, and Kodikara (2003) highlighted the need for equipping students with creativity, flexibility, reflection and evaluation when working with individuals with communication difficulties in contexts where mentoring is scarce and where diverse cultures prevail. It may also be considered crucial to work on the professional trainees' perceptions of diverse populations since stereotypical perceptions may negatively affect intervention with such populations. Pillay (2013) argues that very often education and training of SLPs is carried out only in their native language and that this does not reflect a true picture of the world's population and those with communication difficulties. Hence, he proposes that SLP curricula should focus on SLPs becoming self-sufficient trans-linguistic practitioners. By this he means that SLPs should have generic and clinical skills that enable them to manage efficiently and effectively the cultural and linguistic diversity that they come across in their practice. The strategies that will be recommended below support the recommended conceptual framework, will highlight the importance of having trans-linguistic and multilingual practitioners. This is crucial for future training of SLPs since the world is increasingly becoming multilingual. Hence, we need to adapt to this diversity. For example, the current data on bilingual speech and language acquisition is indicating that bilingual children have different patterns and rate of acquisition of such skills (e.g., Grech \& Dodd, 2008; Stow \& Pert; 2006; So \& Leung, 2006; Salameh, Nettlebladt, \& Norlin, 2003). SLPs need to adapt and adopt tools to assess and manage the culturally and linguistic diverse populations to whom they are increasingly being referred.

It seems that most SLP training establishments in Europe are not addressing the needs of culturally diverse populations and SLP education and training is only just beginning to include units related to multilingualism and multiculturalism (e.g., English programme for European Erasmus student mobility offered by Thomas Moore, Antwerp, Belgium, www.thomasmore.be/slt) Unless SLPs are aware of these 'bilingual characteristics' there is the danger of unfairly identifying an apparent deficiency in language competence (Stow \& Dodd, 2003). A recent European project termed NetQues was conducted and completed in 2013 with the goal of reporting the current state of education and training of speech language pathologists within Europe. This was a multinational collaborative study that ultimately described generic and specific competences that are considered crucial in SLP education. The project involved academics, professional associations and recently qualified SLPs. 65 partners from 31 European countries participated in the study under the leadership of CPLOL, the Standing Liaison Committee of Speech and Language Therapists and Logopaedists (CPLOL, 2013). The project was partly funded by the European Commission under the Erasmus Life Long Learning programme. The results were documented and are currently regarded as the EU-wide agreed common standards of education and practice of speech and language therapy. The generic and specific knowledge aspects, skills and attitudes most 
frequently mentioned as essential to a qualified SLP were compiled. The appreciation of diversity and multilingualism was one of the most agreed-upon generic competences amongst participants, while the importance that the SLP identifies the influence of different situations, environments or contexts on clients' problems was considered an important specific competence that SLPs should have. Additionally, attitudinal and people oriented skills such as empathy and understanding were considered crucial for effective inter-personal relationships between the SLP and clients.

\section{Method-Creating a Conceptual Framework}

\subsection{Perceptions and Competence to Work with Migrant Communities}

Since mobility is also increasing among health care professionals (e.g., the promotion of free movement in the European Union), cross-linguistic and cross-cultural barriers are also being experienced by those delivering care. In particular, this applies to professionals such as SLPs who may not speak the clients' vernacular and are not familiar with their culture. Crowley, Baigorri, Ntim, Bukari, Oseibagyina, Kitcher, and Paintsil (2013) report that given the limited service available to persons with communication difficulties in Ghana, SLPs had to come up with a framework that best fit the circumstances, culture and individuals with communication difficulties. In this way, the SLPs engaged in more effective strategies to advocate for persons with communication difficulties, irrespective of their origin and culture.

Smedley, Stith, and Nelson (2003) report how cultural competency is taking a new meaning with health care service providers in order to increase patients' utilization of services, their satisfaction and compliance and eventually reduce cultural disparities. There is increasing awareness and scientific research regarding how health service providers perceive health-related beliefs and practices of patients from diverse cultural backgrounds and how these compare with specific culture/patient's own beliefs and concepts of health and illness. For example, Maupin and Ross (2012) reported significant conceptual and perceptual variation between Mexican migrants and health care staff (including medical doctors, nurses, nurse practitioners and behavioural health specialists). Following analysis of the data collected the authors concluded and recommended that health service providers should recognize the potential for cultural differences in health-related beliefs and practices and use their knowledge and skills to improve cross-cultural interactions, communication, and intervention outcomes. O'Callaghan McAllister Wilson (2005) report on the imbalances at the health professional level when they work in rural, remote areas and with culturally diverse populations indicating the lack of support, the limited human and work resources as well as the scarcity of opportunities for professional development.

Pillay (2013) argues that when working with migrants SLPs need to apply specific strategies and skills to cater for the diverse linguistic and cultural backgrounds. They need to have efficient interactive communication skills, apply the international phonetic alphabet when analysing speech, use conversational-communication analysis frameworks, make use of electronic resources such as 'translation' facilities (in the absence of interpreters in clinics) and use symbols and non-verbal modes of communication to interact with clients. He also claims that trustworthy qualitative frameworks would need to be applied in the absence of 
quantitative measures and psychometric data. SLPs need to apply such knowledge and skills as to be able to reach differential diagnosis and to distinguish difficulties in such migrant populations that are genuine communication impairments and not merely attempts to acquire the language/s of the host country. Furthermore, Kathard and Pillay (2013) appeal to SLPs to collectively become 'political actors' at all levels to effect change.

\subsection{Perceptions of Migrants about Services Offered}

Battle (2012) explains how communication is embedded in culture. Smith and Reynolds (2002) report studies indicating that cultural differences may affect the clients' perception of service quality and provision. Perceptions and attitudes of migrants who are often culturally diverse individuals should be considered in the assessment, diagnosis and intervention by SLPs. When working with these individuals we need to focus more on their mentality, beliefs and attitudes. Westby (2013) provides food for thought for SLPs working with indigenous populations; this is also applicable to other culturally diverse groups. She urges SLPs to address issues such as what are considered communication impairments in the specific community and how they affect the individual's functioning and quality-of-life. She also invites SLPs to identify the expected outcomes of speech therapy from the clients and their caregivers. Different cultural practices also impact attitudes, such as the need for referral to professional services, including speech and language therapy, the drive for education and literacy skills development as well as the need to interact with individuals coming from other cultural backgrounds. Following one-on-one interviews with 40 immigrants who were seeking refugee status in Malta and were at the time residing in 3 detention centres, Grech and Cheng (2010) reported some of the feelings and attitudes of these migrants. There was a tendency for the migrants to be suffering from culture shock and feeling marginalized. A few migrants seemed to be adjusting better to the new culture and indicated some proficiency in the vernacular of the country where they landed on. A high proportion of the immigrants indicated feelings of dissatisfaction with the service they were receiving in the host country. More than half of the respondents complained of experiencing difficulties with communicating in Malta and about one third of them were dissatisfied with their communication with the Maltese community. Some also expressed dissatisfaction with the health care service that they were receiving in Malta, while most of the respondents $(83 \%)$ were unaware that the speech therapy service exists. Suggestions posed by the migrants to improve the service they are receiving in the host country included opportunities to learn to read and write in English and/or Maltese, transportation to the hospital and better work opportunities. The authors concluded that the core underlying issue of the migrants' dissatisfaction was the difficulty they encountered in communicating.

\subsection{Developing a Framework of SLP Practice for Migrants}

Wylie, McAllister, Davidson, and Marshall (2013) urge SLPs to provide an equitable and relevant service to persons with communication and swallowing difficulties bearing in mind the different cultures and settings that they may be living in. Consequently, SLPs are requested to think laterally and design new approaches that are culturally relevant, holistic, accessible, sustainable and responsive. The authors also push SLPs to advocate for their 
clients at the national and if possible international level as well as within the organization in which they provide the service and within their own practice. It is important that SLPs adopt procedures of assessment and intervention that are more relevant to the client's linguistic and cultural needs. Various frameworks and models have developed to address care and cultural diversity, particularly in its application to nursing. Not all models succeed in the double goal of reaching out to the needs of the client, family and community while providing appropriate multi-systemic support that is tailored to the sociolinguistic and cultural needs of the persons with disabilities. Standards of practice for "culturally competent care" have been suggested. However, Albarran et al. (2011) argue that such frameworks often consider the culturally diverse group as the 'marginalised ethnic community' reflecting a narrow view of transcultural caring and seemingly privileges or undermines specific cultures. The authors support the transcultural care view of phasing out cultural stereotypes and instead highlighting similarities and differences within and across cultures and focusing on the individuality and uniqueness of clients. The same authors reviewed the European literature on cultural care and concluded that this was not communicated within the health care 'science'. There is a lack of clear framework for the relationship between care practices and cultural care. A framework of care that embraces culture as an integral factor is needed. More recently, professional care is being perceived as a complex integration of understanding the individual holistically and merging evidence-based knowledge and skills to optimize quality of life in specific clinical settings.

Wylie, McAllister, Davidson, and Marshall (2013) emphasised the need to involve SLPs in service delivery models that provide a more balanced and culturally appropriate service and access to speech therapy to underserved individuals with communication disabilities. A framework of the knowledge and skills expected of SLPs to effectively manage clients with communication and swallowing disorders who are members of such communities is crucial bearing in mind the needs, values, attitudes and expectations of the client and family. Giger and Davidhizar's (2004) transcultural model supports this philosophy. It was originally developed for nursing care but is claimed to be applicable to other health and social care professions. Within this framework the authors recommend the assessment of six cultural phenomena when working with service users. These include communication (in this context referring to how an individual transmits and preserves his culture via human interaction); space (acknowledging and respecting one's personal space within which s/he interacts); social organization (family beliefs, values and networking); time (referring to cultural orientation of time in respect of the past, present and future); environmental control (referring to the planning and control of factors that affect the individual and his/her loved ones); and biological variations (including development and diseases/disorders as experienced within specific cultures that may be influenced by factors such as diets or gender). The authors claim that these factors help practitioners to understand the client's cultural perspective and the impact that each of these factors has on the individual's health.

Albarran et al. (2011) came up with a transcultural, working framework that places the service user as central to the decision-making, an approach which is increasingly becoming desirable. This framework of care focuses on humanizing values while addressing the specific 


\section{Al Macrothink

needs of the person irrespective of culture and orientation; in particular, the functional communication needs of persons with communication difficulties. The framework acknowledges the influencing factors that impinge on an individual's life style and health such as the home and community, heritage, history, economic status, social biology and spirituality. The core principle of humanization is embraced in the framework while ensuring that there is working partnership between the practitioner and clients/patients to better understand their cultural beliefs and values.

Such a model promotes a change in perceptions of individuals, communities, and policymakers about the equal rights of human beings irrespective of whether these are disabled people, migrants and/or low income communities. Such individuals should have the same privileges and benefits from services and other opportunities as anyone else. The model acknowledges that in order to achieve this balance extra resources may be required that cater for cultural, linguistic and social diversity.

\section{Results}

Figure 1 below simplifies this holistic model indicating all the stake holders that need to be engaged in decision-making and activities across all sectors (e.g., health, education and social) as this is driven by a human rights approach.

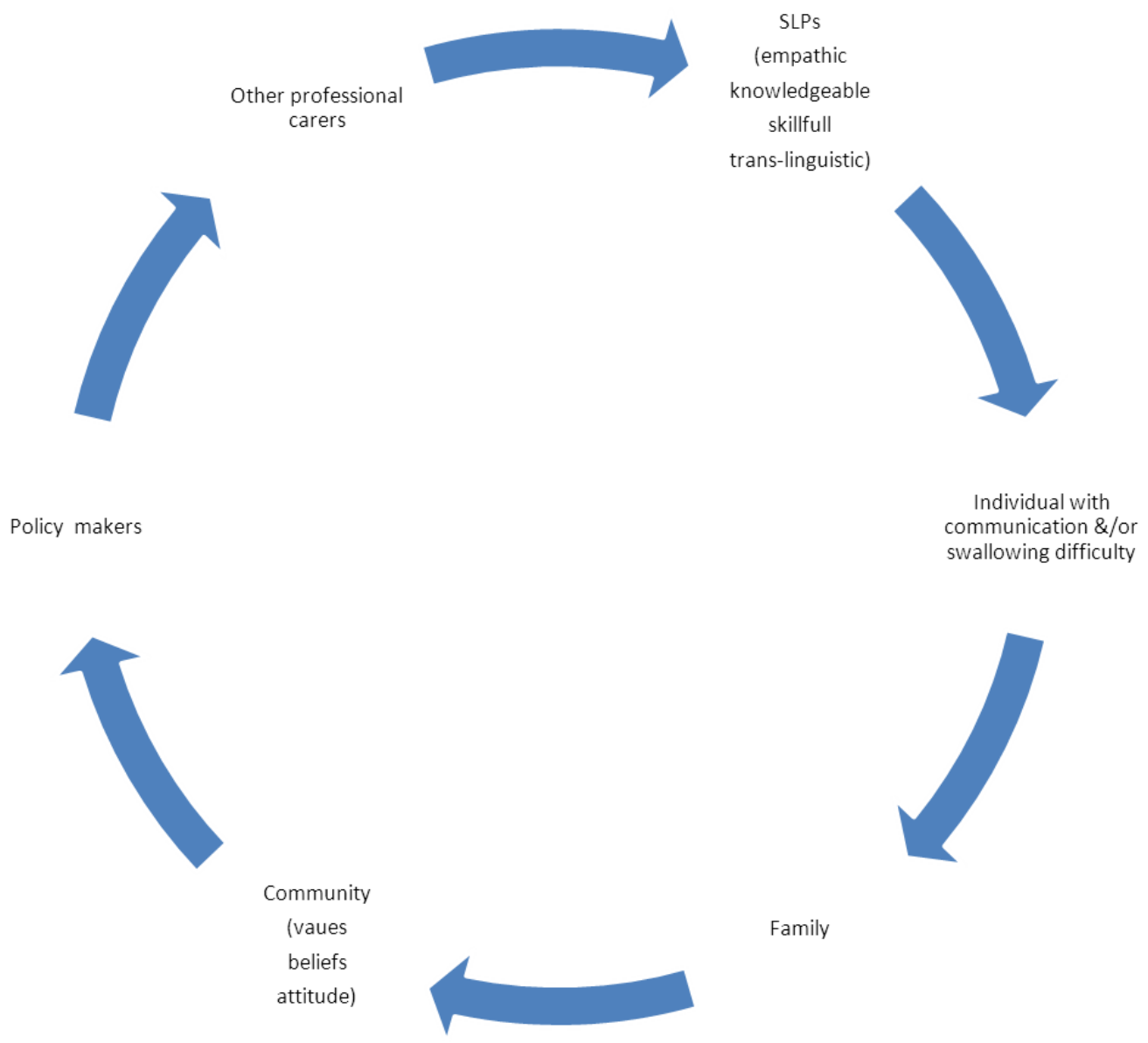

Figure 1. A conceptual framework for speech therapy service to migrant populations 


\section{Discussion}

\subsection{Strategies Focusing on Cultural Needs}

The relevant literature, research findings and conceptual framework discussed in this paper give rise to the recommendation of strategies aimed at improving the equity of health care, with particular focus on speech therapy service to migrant families. Some of these strategies are mentioned below. They are sub-grouped in terms of what could be done by governments, SLPs and training establishments, respectively.

\subsubsection{Governmental Strategies}

The appointment of a board of health care professionals to monitor the living conditions of migrants, particularly detention centres, MSF (2009) recommended that men and women as well as minors should live in separate quarters, having each a separate bed and males, without each group having to share water and sanitation facilities; access to exterior space on a regular basis was also considered crucial. The implementation of this strategy would reflect positively on the migrants' health and wellbeing. However, the increasing numbers of irregular migrants in Europe, particularly in Malta and Italy, have become a challenge to the respective countries, both in terms of the provision of space/temporary residence for the migrants as well as the economic issues that arise in providing humanitarian support to them.

An increase in awareness of health services amongst the migrant families is important, particularly when they are living in small rural communities. It should be an objective of policy makers to target this issue because individuals who may need speech therapy or may wish to refer family members for this service may not know how and where to access it. For example, when Grech and Cheng (2010) tried to capture the immigrants' awareness of the speech therapy service, most of the respondents were unaware that this service existed. One obstacle to implementing this practice is the difficulties encountered in communicating with the migrants; another issue is related to their attitude and beliefs as well as the migrants' perception of the need for them or their family members to access the speech therapy service. When Grech and Cheng asked some of the immigrants they interviewed if they were worried about their minors' acquisition of speech and language, most of them replied that this was not an issue for them as they were more concerned about their financial situation as well as the fact that they were being detained for far too long.

Health care services should be provided with the assistance of an interpreter/cultural mediator. This should enhance better communication between the clinician and the migrant and a better understanding of their needs and worries. Consultations with migrant associations should be encouraged to identify their needs. It is important that the migrant community is consulted before any decisions are made by governments pertaining to its welfare and wellbeing. The government should come up with strategies to mitigate xenophobia. A relevant project JUST/2011/PROG/AG/1902, entitled "I'm Not a Racist, But ..." (NCPE, 2012) was implemented in Malta to raise awareness on racial discrimination, promote cultural diversity and empower the African community to advocate for their rights. The importance of increasing funding for more SLPs and expanded speech pathology services to work with 
these communities cannot be over-stated; introducing incentives to attract SLPs to work with cross-linguistic and cross-cultural populations should also be considered by employers. For example, continuing professional development opportunities to enhance and support clinicians working with the culturally and linguistically diverse populations should be sponsored by employers.

Roulstone and Harding (2013) emphasize the need to facilitate accessibility of SLP services and promote the value of this service. Cheng (2013) reminds us that accessibility refers to geographical and linguistic access. In the case of culturally diverse populations she encourages the involvement of the local stake holders to ensure sustainability of any project that may be introduced for persons with communication impairment. Schemes should be introduced or enhanced to enable migrants to travel and access better speech pathology services. Decisions regarding service location, level of intervention targeted, who will deliver the service and the focus of intervention should be taken bearing in mind the clients' needs and the available resources (Wylie, McAllister, Davidson, \& Marshall, 2013). This way accessibility to the service would be easier for migrants. Governments should make more effort to provide easier access to telecommunications to all. It is acknowledged that most asylum seekers and illegal immigrants may not have easy access to telephones, radio, television and/or the Internet. Consequently, as reported by Greenstock et al. (2012) these persons may not be aware that such technology could be a means to access health information and health care. Besides, governments need to consider educating/training the culturally and linguistically diverse communities in e-health literacy given the modernization developments related to health care consumption.

\subsubsection{SLP Strategies}

SLPs should primarily become aware of their own beliefs and values in order to be able to acknowledge similarities and differences in communication styles, values and beliefs with the individuals whom they serve (Battle, 2012). They should be sponsored to receive such training and support in order to more effectively understand and serve culturally diverse populations. Besides being sensitive to the attitudes and values of culturally diverse individuals and family members, the different communication styles (verbal and nonverbal) should be considered by clinicians to be culturally effective. Perhaps understanding basic indigenous gestures and key utterances of migrants could be the first step to optimizing communication between client and clinician. It is important for SLPs to approach parents/carers of children with communication difficulties to find out what they are expecting the SLPs to work on. It is crucial to focus more on how the clients need to function better in the family and community and address intervention accordingly. This type of service is in line with the International Classification of Functioning, Disability, and Health (ICF) (World Health Organization, 2001). Crowley and colleagues (2013) report the project where they developed alternative and augmentative communication cards so that children could use them to purchase food in the local market as expected of children within that culture. SLPs need to listen to what the clients are trying to tell them and try to address their needs to the best of their knowledge, skills and resources. SLPs need to become more involved outside the health and service provision field: they should involve themselves cross-sectorally and should also 
engage in debates with policy makers and politicians as advocates of individuals with communication difficulties (Wickenden, 2013). The author emphasizes the need for SLPs to encircle human rights approaches and broaden frameworks of inclusion in light of global initiatives, such as what is advocated by WHO in relation to community-based rehabilitation (World Health Organization, 2011). Since communication disorders per se are rarely specifically mentioned within wider disability issues and are often merged with sensory impairment it is important that SLPs advocate for persons with communication difficulties, particularly those within migrant families. Otherwise, they may not be able access speech therapy services easily and this would have economic, health, educational and social implications.

Given that language plays a major role in cultural identity and self-concept, SLPs should gear intervention so that their clients acquire sociolinguistic and discourse competency up to their maximum potential. Wickenden (2013) states that traditional individual therapy in its conventional form may not make much difference to people with communication impairment where poverty and marginalization are major issues. She claims that there is a need for SLPs, professional associations and policy makers to share common goals in promoting the rights and needs of individuals with communication difficulties. When working in cross-linguistic and culturally diverse settings it is crucial that we involve families, educators and other caregivers who originate from these indigenous groups. Lowell (2013) encourages SLPs to involve indigenous people (referring to those in Australia) to collaborate with them in planning the service to them as these people know better what their difficulties are, what they need and how they want SLPs to respond to them. She claims that this collaboration would guarantee sustainability and equity of service to these populations.

\subsubsection{Training Programmes' Strategies}

Teaching establishments must provide courses in the areas of bilingualism, assessment of culturally and linguistically diverse clients, planning and delivery of culturally relevant intervention in order to effectively prepare clients to live meaningfully and respectably within their own cultural and linguistic context. SLP students must be given opportunities through research and practicum to develop the skills necessary to manage clients with diverse backgrounds effectively.

\subsection{Cost Benefit Analysis}

The financial aspect of SLP service provision to irregular migrants, methodology and their effectiveness need to be explored and will be briefly discussed below. It is debatable as to how to evaluate the strategies recommended above in terms of cost effectiveness analysis since as indicated by the US Public Health Service guidelines (Gold, Siegel, Russell, \& Weinstein, 1996), in health care this should only be considered to assist with decision making rather than a procedure on which health service delivery is based. In the case of speech therapy service there is a significant proportion of the clienteles who do not form part of the work force (i.e., children and elderly as well as adults with severe disability who may be unable to be enrolled in gainful employment). Hence, the traditional labour market methods for cost effectiveness analysis may be inappropriate in this instance. This would also be the 
case with working out cost effectiveness of speech therapy service to irregular migrants, since they are often unemployed or have limited income. Raftery (1999) claims that in any case, the issue of how to calculate cost-effectiveness in welfare economics, as applied to healthcare is still contentious. He recommends analysis in terms of cost per life year or per 'unit' of health gain. There is still the issue that the total benefit of some health care programmes may not be easy to calculate given that long term care and prognosis may be unclear, especially when there is comorbidity of conditions (e.g., a child's speech, language, cognitive and hearing difficulties are secondary to a specific syndrome). The argument put forward here is in favour of analysing in more practical terms such as the cost benefits of implementing these strategies in terms of enhancing quality of life and wellbeing as well as the importance of monitoring and offering continuity of the service provision.

Rechel, Mladovskya, Ingleby, Mackenback, and McKee (2013) report that there is limited data related to the effectiveness of interventions to improve health service provision to migrants. They place the blame on limited research funding in this area. Following a systematic literature review Mladovskya, Rechel, Ingleby, and McKee (2012) concluded that the majority of EU member states do not seem to have a record on the health of migrants; thus monitoring and enhancing the health of migrants is difficult. Data on the use of health care by migrants were found for 11 out of the 27 member states. When such records were available these were limited to secondary prevention, i.e., involving early detection of disease to avoid its development by, for example, using screening programmes. Ideally, primary prevention should be engaged. This entails preventing the occurrence of disease, impairment or injury, as via immunization programmes. In case of speech therapy, while most EU states are addressing secondary prevention, there are still gaps in service related to primary prevention. For example, although universal neonatal screening for hearing impairment is implemented in European countries such as Belgium and the United Kingdom, other countries such as Malta are still planning to initiate this programme.

Overcoming language barriers is a strategy that is considered crucial to allowing linguistically diverse migrants to access the health system optimally, particularly in the case of speech therapy. However, implementation of this strategy adds costs to service providers, employers and governments. It can be argued that the extra costs related to identification of speech and language difficulties would be beneficial given the gains in quality of life for individuals whose communication skills improve on intervention. In the case of children, the repercussions of late identification of a developmental communication disorder would have direct negative effects on learning, behaviour and social interaction as well as wellbeing. The later a child is identified with a speech and/or language difficulty and consequent therapy is provided, the more costly it becomes as a result of the additional support services required to ameliorate the psycho-cognitive-linguistic situation. Hence, prevention, early identification and intervention would in the long run be cost beneficial. If anything, early diagnosis saves costs of additional diagnostic tests. Similarly, in the case of elderly and adult clients, early intervention should reduce the time of service delivery and also prevent further costly complications.

Needless to say, expansion and upgrading of services entails additional resources, in 
particular financial ones. Given that individuals with communication difficulties often do not present with life threatening situations; any health system with a stringent budget may not consider this service a priority. However, other sources of funding and resources could be tapped to aid with the promotion and implementation of better and more accessible speech therapy to irregular migrants in Malta and Europe, in particular. For example, a recently completed project JUST/2011/PROG/AG/1902, entitled "I'm Not a Racist, But ..." (NCPE, 2012) was implemented in Malta to raise awareness on racial discrimination, promote cultural diversity and empower the African community to advocate for their rights. The European Commission offers plenty of opportunities for its member states to apply for 'humanitarian' project funding such as the one above. Upon interviewing irregular migrants, it was noted that a number of them had higher levels of education and were also multilingual. Some of these individuals are being asked to act as interpreters for their more vulnerable and dependent colleagues. These types of resources should be sought and used optimally. A number of NGOs such as the Jesuit Refugee Service are already offering a lot of assistance to the migrants, most of which is voluntary. Such exemplary resources could be supported by other internal and external bodies in order to enhance and further develop the good work that is being geared towards supporting irregular migrants. In terms of outreach for speech therapy service in this community, it would be ideal if supervised clinical placements could be offered to SLP students to work directly with irregular migrant minors within open centres. Opportunities could also be provided for adult irregular migrants to participate in workshops for adults in relation to stimulating speech and language (spoken and written) acquisition and preventing delay and impairment. While such services could be free to migrants they would be of mutual benefit since students would be gaining direct exposure to working with these vulnerable communities.

\section{Conclusion}

This paper reviewed services offered to asylum seekers and those seeking refugee status migrants in Europe with particular focus given to those individuals arriving on Maltese territories. It identifies barriers and challenges that require attention. The health care services offered to migrants are reviewed in the light of attitudes and expectations. Professional perceptions and competences to work with these populations are also evaluated as well as perceptions of migrants about services offered to them. Issues related to equitable professional practice and the training of health care professionals to address needs of the cultural diverse community are discussed. The authors draw up a framework that could be applied to enhance services to the culturally and linguistically diverse individuals, particularly speech therapy. Strategies and recommendations to implement the conceptual framework are suggested. Westby (2013) stresses that speech therapy services have to be planned bearing in mind cultural diversity with respect to beliefs, needs and requirements. Failure to acknowledge cultural differences can reflect on the professional's cultural competency; on the other hand the assumption that cultural difference is non-existent is equally problematic. In accordance with the biopsychosocial model as referred to in the World Disability Report, SLPs are expected to acquire deeper understanding of culture and learn how to share their knowledge and skills wherever they work. Mutual trust is crucial 
when working with culturally and linguistically diverse individuals; this develops over time and allows sincere discussions of how to work together to enhance the communication skills of the individual. Attempts to build capacity must be tailored to the available technologies in a particular country or context. Global initiatives need to increase for the enrollment of high quality research related to prevention, assessment and intervention of individuals with communication and swallowing disorders across diverse populations. It is also crucial to educate and train SLP students to acquire better knowledge, skills, cultural sensitivity and attitudes to be able to work more effectively with culturally diverse populations. As Stewart and Gozales (2002) suggested, SLP students need to be creative, enhance their problem solving skills and to learn to lobby for the needs of their clients effectively. We need to become more innovative with our health care service strategies and be more diverse. Theodoros (2012) justifies this need for change in relation to increasing cost and demand for healthcare service, particularly with the demographic shift towards the ageing population. She also claims that the advances in technology and neuroscience also urge SLPs to shift their intervention focus according to these trends. A further justification for coming up with new models of service delivery is the increasing culturally diverse populations and mobility worldwide. Indeed, novel intervention approaches supported by evidence-based/efficacy studies would better address contemporary society and the trend to empower clients/carers and engage them in self-management. Wickenden (2013) states that traditional individual therapy in its conventional form may not make much difference to people with communication impairment where poverty and marginalization are major issues. She claims that there is a need for SLPs, professional associations and policy makers to share common goals to promote the rights and needs of individuals with communication difficulties.

In light of the World Report on Disability, SLPs need to shift their professional focus to see themselves as capacity builders of other service providers rather than solely as clinicians working with individual clients. Together with other care providers they have a key role to empower those who perceive themselves as being 'powerless and vulnerable', with particular reference to individuals with communication difficulties who come from culturally diverse backgrounds. SLPs need to understand the social, cultural, linguistic, and local needs of individuals with communication and swallowing difficulties in order to provide tailor-made management that would be effective and sustainable. Migration and cultural diversity is on the rise and is spreading across the globe. Health service provision should cater for this reality in a non-discriminatory way. Culturally diverse communities need to be involved in planning, implementation and evaluation of activities, particularly concerning the promotion of equality (NCPE, 2012).

\section{References}

Albarran, J. W., Rosser, E., Bach, S., Uhrenfeldt, L., Lunderg, P., \& Law, K. (2011). Exploring the development of a cultural care framework for European care science. International Journal of Qualitative Studies Health Well-being, 6, 1-11. http://dx.doi.org/ 10.3402/qhw.v6i4.11457

Battle, D. (2012). Communication Disorders in Multicultural Populations (4th ed.). St Louis: 
Elsevier Mosby.

Bigo, D., \& Guild, E. (2005). Policing in the Name of Freedom. In D. Bigo, \& E. Guild (Eds.), Controlling Frontiers: Free Movement Into and Within Europe. Aldershot: Ashgate Publishing.

Bradford, S., \& Clark, M. (2014). Strangers on the Shore: Sub-Saharan African "Irregular" Migrants in Malta. Journal of Immigrant \& Refugee Studies, 12, 9-26. http://dx.doi.org/ $10.1080 / 15562948.2013 .877703$

CESCR. (2000). General Comment No. 14. The Right to the Highest Attainable Standard of Health. UN Doc. E/C.12/2000/4.

Cheng, L. (2103). Knowledge transfer between minority and majority world settings and its application to the World Report on Disability. International Journal of Speech-Language Pathology, 15(1), 65-68. http://dx.doi.org/10.3109/17549507.2012.729862

Commissioner for Human Rights. (2011). Report by Thomas Hammarberg, Commissioner for Human Rights of the Council of Europe, following his visit to Malta from 23 to 25 March 2011. Retrieved from https://wcd.coe.int/wcd/ ViewDoc.jsp?id=1797917

CPLOL. (2013). Network for Tuning Standards and Quality of Education Programmes in Speech and Language Therapy/Logopaedics across Europe (NetQues) Project Report. No. 177075-LLP-1-2010-1-FR-ERASMUSENWA. Retrieved from http://www.netques.eu

Crowley, C., Baigorri, M., Ntim, C., Bukari, B., Oseibagyina, A., Kitcher, E., ... Laing, A. (2013). Collaborations to address barriers for people with communication disabilities in Ghana: Considering the World Report on Disability. International Journal of Speech-Language Pathology, 15(1), 53-57. http://dx.doi.org/10.3109/17549507.2012.743036

Dauvergne, C. (2008). Making People Illegal: What Globalisation Means for Migration and Law. Cambridge: Cambridge University Press. http://dx.doi.org/10.1017/CBO978051 1810473

De Souza, R. (2008). Wellness for all: The possibilities of cultural safety and cultural competence in New Zealand. Journal of Research in Nursing, 13, 125-135. http://dx.doi.org/ $10.1177 / 1744987108088637$

European Network Against Racism. (2010). Racism and discrimination in Malta. ENAR Shadow Report 2009-1010. Brussels, Belgium: ENAR.

Footer, K. H. A., \& Rubinstein, L. S. (2013). A human rights approach to Health Care in Conflict. International Review of the Red Cross, 95(889), 167-187. http://dx.doi.org/10.1017/ S1816383113000349

Gerard, A., \& Pickering, S. (2012). The crime and punishment of Somali women's extra-legal arrival in Malta. British Journal of Criminology, 52, 514-533. http://dx.doi.org/10.1093/ bjc/azr094

Giger, J. N., \& Davidhizar, R. E. (2004). Transcultural Nursing: Assessment and Intervention 
(4th ed.). St Louis: Mosby.

Gold, M. R., Siegel, J. E., Russell, L. B., \& Weinstein, M. (1996). Cost Effectiveness in health and medicine. Oxford University Press.

Grech, H., \& Cheng, L. (2010). Communication in the migrant community in Malta. Folia Phoniatrica et Logopaedica, 5, 246-254. http://dx.doi.org/10.1159/000314788

Grech, H., \& Dodd, B. (2008). Phonological acquisition in Malta: A bilingual language learning context. International Journal of Bilingualism, 12(3), 155-171. http://dx.doi.org/ $10.1177 / 1367006908098564$

Greenstock, L., Woodward-Kron, R., Fraser, C., Bingham, A., Naccarella, L., Elliott, C., \& Morris, M. (2012). Telecommunications as a Means to Access Health Information: An Exploratory Study of Migrants in Australia. J. Public Health Research, 1(3), 216-221. http://dx.doi.org/10.4081/jphr.2012.e34

Hartley, S. (1998). Service development to meet the needs of 'people with communication disabilities' in developing countries. Disability and Rehabilitation, 20, 277-284. http://dx.doi.org/10.3109/09638289809166083

Kathard, H., \& Pillay, P. (2013). Promoting change through political consciousness: A South African speech-language pathology response to the World Report on Disability. International Journal of Speech-Language Pathology, 15(1), 84-89. http://dx.doi.org/10.3109/17549507. 2012.757803

JRS (Jesuit Refugee Service). (2007). Civil Society Report on Administrative Detention of Asylum Seekers and Illegally Staying Third Country Nationals in the 10 New Member States of the European Union: Regional Report. Malta: JRS.

Leserman, P. P. M. (2002). Early childhood education and care for children from low-income or minority backgrounds. OECD.

Lowell, A. (2013). From your own thinking you can't help us: Intercultural collaboration to address inequities in services for Indigenous Australians in response to the World Report on Disability. International Journal of Speech-Language Pathology, 15(1), 101-105. http://dx.doi.org/10.3109/17549507.2012.725770

Mainwaring, C. (2012). Constructing a Crisis: The Role of Immigration Detention in Malta. Popuation, Space Place, 18, 687-700. http://dx.doi.org/10.1002/psp.1721

Maupin, J. N., \& Ross, N. (2012). Expectations of similarity and cultural difference in conceptual models of illness: A comparison of medical staff and Mexican migrants. Human Organization, 71(3), 306-316. Retrieved from http://search.proquest.com/docview/105580 6662 ? accountid $=27934$

Médicins Sans Frontièrs (MSF). (2009). Not Criminals. Belgium: Médicins Sans Frontièrs Brussels Operational Centre.

Mladovskya, P., Rachel, B., Ingleby, D., \& McKee, M. (2012). Responding to diversity: An 
exploratory study of migrant health policies in Europe. Health Policy, 10, 1-9. http://dx.doi.org/10.1016/j.healthpol.2012.01.007

National Statistics Office. (June 19, 2014). News Release, 116/2014: Malta.

NCPE (National Commission for the Promotion of Equality). (2012). I'm Not Racist, But ... Final Report. Malta: NCPE.

O'Callaghan, A. M., McAllister, L., \& Wilson, L. (2005). Barriers to accessing rural paediatric speech pathology services: Health care consumers' perspectives. Australian Journal of Rural Health, 13, 162-171. http://dx.doi.org/10.1111/j.1440-1854.2005.00686.x

Pickering, S., \& Gerard, A. (2011). The Journey to the Border: Continuums of Crossing. In S. Pickering (Ed.), Women, Borders and Violence: Current Issues in Asylum, Forced Migration and Trafficking (pp. 17-37). London: Springer. http://dx.doi.org/10.1007/978-1-44190271-9 2

Pillay, M. (2013). Can the subaltern speak? Visibility of international migrants with communication and swallowing disabilities in the World Report on Disability. International Journal of Speech-Language Pathology, 15(1), 79-83. http://dx.doi.org/10.3109/17549507. 2012.757708

Pisani, M., \& Azzopardi, A. (2008). The odyssey of the young female asylum seeker: Engaging critically on gendered forced migration. Forum, 21, 128-135.

Raftery, J. (1999). Methodological limitations of cost-effectiveness analysis in health care: implications for decision making and service provision. Journal of Evaluation in Clinical Practice, 5(4), 361-366. http://dx.doi.org/10.1046/j.1365-2753.1999.00179.x

Rechel, B., Mladovskya, P., Ingleby, D., Mackenback, J., \& McKee. (2013). Migration and health in an increasingly diverse Europe. The Lancet, 381(9873), 1235-1245. http://dx.doi.org/10.1016/S0140-6736(12)62086-8

Rodriguez, D. (2005). A Conceptual Framework of Bilingual Special Education Teacher Programs. In J. Cohen, K. T. McAlister, K. Rolstad, \& J. MacSwan (Eds.), Proceedings of the $4^{\text {th }}$ International Symposium on Bilingualism (pp. 1960-1969). Somerville, MA: Cascadilla Press.

Roulstone, S., \& Harding, S. (2013). Defining communication disability in under-served communities in response to the World Report on Disability. International Journal of Speech-Language Pathology, 15(1), 27-3. http://dx.doi.org/10.3109/17549507.2012.727870

Salameh, E.-K., Nettlebladt, U., \& Norlin, K. (2003). Assessing phonologies in bilingual Swedish-Arabic children with and without language impairment. Child Language Teaching and Therapy, 19, 338-364. http://dx.doi.org/10.1191/0265659003ct258oa

Smedley, B., Stith, A., \& Nelson, A. (Eds.). (2003). Unequal Treatment: Confronting Racial and Ethnic Disparities in Health Care. Washington, D.C.: Institute of Medicine, National Academies Press. 
Smith, A., \& Reynolds, N. (2002). Measuring cross-cultural service quality: A framework for assessment. International Marketing Review, 19(5), 450-481. http://dx.doi.org/10.1108/026 51330210445

So, L., \& Leung, S. (2006). Phonological Development and Disorders in Children: A Multilingual Perspective. Clevedon: Multilingual Matters.

Stewart, S., \& Gonzalez, L. (2002). Serving a diverse population: The role of speech-language pathology professional preparation programs. Journal of Allied Health, 31(4), 204-16.

The Sunday Times of Malta. (July 14, 2013). Government accuses Opposition of obstructing efforts to put migration on EU agenda. Malta: Progress Press.

Stow, C., \& Dodd, B. (2003). Providing an equitable service to bilingual children in the UK: A review. International Journal of Language and Communication Disorders, 38(4), 351-377. http://dx.doi.org/10.1080/1368282031000156888

Stow, C., \& Pert, S. (2006). In Z. Hua \& B. Dodd (Eds.), Phonological Development and Disorders in Children: A Multilingual Perspective. Clevedon: Multilingual Matters.

Topouzkhanian, S., \& Mijiyawa, M. (2013). A French-speaking speech-language pathology program in West Africa: Transfer of training between Minority and Majority World countries. International Journal of Speech-Language Pathology, 15(1), 58-64. http://dx.doi.org/ $10.3109 / 17549507.2012 .757802$

Theodoros, D. (2012). New Era in Speech-Language Pathology Practice: Innovation and Diversification. International Journal of Speech-Language Pathology, 14(3), 189-199. http://dx.doi.org/10.3109/17549507.2011.639390

UNHCR. (2012). What do you think? A report on public perception on refugees and migrants in Malta. Malta: Floriana.

UN High Commission for Refugee. (2009). Observations on Greece as a Country of Asylum. Geneva: Office for the United Nations High Commission for Refugees.

Westby, C. (2013). Implementing recommendations of the World Report on Disability for indigenous populations. International Journal of Speech-Language Pathology, 15(1), 96-100. http://dx.doi.org/10.3109/17549507.2012.723749

Wickenden, M. (2013). Widening the SLP lens: How can we improve the wellbeing of people with communication disabilities globally. International Journal of Speech-Language Pathology, 15(1), 14-20. http://dx.doi.org/10.3109/17549507.2012.726276

Wickenden, M., Hartley, S., Kariyakaranawa, S., \& Kodikara, S. (2003). Teaching speech and language therapists in Sri Lanka: Issues in curriculum, culture and language. Folia Phoniatrica et Logopedica, 55, 314-321. http://dx.doi.org/10.1159/000073255

World Health Organization and The World Bank. (2011). World Report on Disability. Geneva: World Health Organization. Retrieved January 16, 2012, from http://www.who.int/disab ilities/world_report/2011/report/en 


\section{Macrothink}

Journal of Educational Issues

ISSN 2377-2263

2016, Vol. 2, No. 2

World Health Organization. (2001). ICF: International Classification of Functioning, Disability and Health. Geneva, Switzerland: World Health Organization.

Wylie, K., McAllister, L., Davidson, B., \& Marshall, J. (2013). Changing practice: Implications of the World Report on Disability for responding to communication disabilities in underserved populations. International Journal of Speech-Language Pathology, 15, 1-13. http://dx.doi.org/10.3109/17549507.2012.727870

Xuereb, P. G. (Ed.). (2012). Migration and Asylum in Malta and the European Union: Rights and Realities. Malta: Malta University Press.

\section{Notes}

Note 1. In this context this term refers to persons running away from persecution, conflict or abuse of human rights as recognized under international law.

Note 2. In this context this term refers to persons having to leave their country of origin because of inaccessibility of basic needs such a food, water, health care, shelter and/or insecure or unsafe environment.

\section{Copyright Disclaimer}

Copyright for this article is retained by the author(s), with first publication rights granted to the journal.

This is an open-access article distributed under the terms and conditions of the Creative Commons Attribution license (http://creativecommons.org/licenses/by/3.0/). 